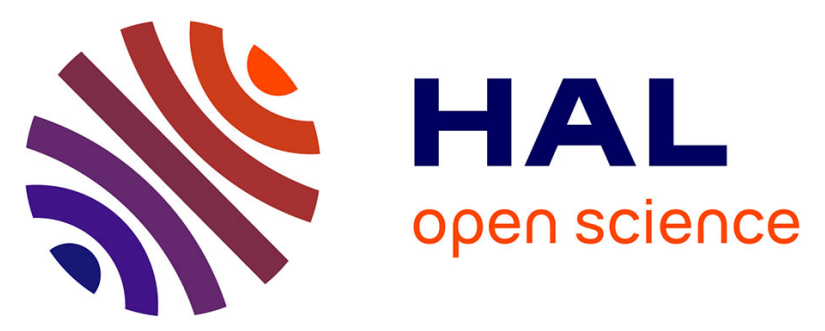

\title{
Nanoparticle Assembling through Click Chemistry Directed by Mixed SAMs for Magnetic Applications
}

Mathias Dolci, Delphine Toulemon, Zaineb Chaffar, Jean-Luc Bubendorff, Frederik Tielens, Monica Calatayud, Spyridon Zafeiratos, Sylvie Bégin-Colin, Benoît Pichon

\section{To cite this version:}

Mathias Dolci, Delphine Toulemon, Zaineb Chaffar, Jean-Luc Bubendorff, Frederik Tielens, et al.. Nanoparticle Assembling through Click Chemistry Directed by Mixed SAMs for Magnetic Applications. ACS Applied Nano Materials, 2019, 2 (1), pp.554-565. 10.1021/acsanm.8b02152 . hal02162505

\section{HAL Id: hal-02162505 \\ https://hal.sorbonne-universite.fr/hal-02162505}

Submitted on 26 Aug 2019

HAL is a multi-disciplinary open access archive for the deposit and dissemination of scientific research documents, whether they are published or not. The documents may come from teaching and research institutions in France or abroad, or from public or private research centers.
L'archive ouverte pluridisciplinaire HAL, est destinée au dépôt et à la diffusion de documents scientifiques de niveau recherche, publiés ou non, émanant des établissements d'enseignement et de recherche français ou étrangers, des laboratoires publics ou privés. 


\title{
Nanoparticle Assembling through Click Chemistry Directed by Mixed SAMs for Magnetic Applications
}

\author{
Mathias Dolci, ${ }^{\dagger}$ Delphine Toulemon, ${ }^{\dagger}$ Zaineb Chaffar, ${ }^{\dagger}$ Jean-Luc Bubendorff, ${ }^{\dagger}$ Frederik Tielens, ${ }^{\S}, \|_{\odot}$ \\ Monica Calatayud, ${ }^{\perp}$ Spyridon Zafeiratos, ${ }^{\# \oplus}$ Sylvie Begin-Colin, ${ }^{\dagger \oplus}$ and Benoit P. Pichon ${ }^{*}, \dagger, \nabla \odot$ \\ ${ }^{\dagger}$ CNRS, UMR 7504, Institut de Physique et Chimie des Matériaux de Strasbourg, Université de Strasbourg, F-67034 Strasbourg, \\ France \\ ${ }^{\ddagger}$ CNRS, Institut de Science des Matériaux de Mulhouse, Université de Strasbourg (UdS)-Université de Haute Alsace (UHA), 3b \\ rue Alfred Werner, F-68093 Mulhouse, France \\ ${ }^{\S}$ CNRS, Collège de France, Laboratoire de Chimie de la Matière Condensée de Paris (LCMCP), Sorbonne Université, F-75005 \\ Paris, France \\ "General Chemistry (ALGC), Vrije Universiteit Brussel (Free University Brussels, VUB), Pleinlaan 2, 1050 Brussels, Belgium \\ ${ }^{\perp}$ CNRS, UMR 7616, Laboratoire de Chimie Théorique (LCT), Sorbonne Université, F-75005 Paris, France \\ ${ }^{\#}$ CNRS, UMR 7515, Institut de Chimie et Procédés pour l'Energie, l’Environnement et la Santé, Université de Strasbourg, F-67087 \\ Strasbourg, France \\ ${ }^{\nabla}$ Institut Universitaire de France, 1 rue Descartes, F-75231 Paris, France
}

Supporting Information

\begin{abstract}
Click" chemistry, used to promote nanoparticle assemblies, is a powerful strategy which has emerged very recently to control the spatial arrangement of nanoparticles onto surfaces. Such a strategy may be of high interest for applications such as magnetic recording media or magnetic sensors which are based on the fine control of the collective properties of nanoparticles. Nevertheless, self-assembly driven by clickable functional groups still remains to be understood. Mixed self-assembled monolayers (SAMs) of alkane-thiol molecules were used to control the spatial arrangement of nanoparticles onto gold substrates. This approach was combined with click chemistry in order to control the immobilization of nanoparticles on selective areas through specific copper catalyzed alkyne-azide cycloaddition (CuAAC) reaction. Mixed SAMs consist of co-adsorbed 11-(undec-1-ynyl)thiol (S-CC) and 12-(dodecane)thiol (S$\left.\mathrm{CH}_{3}\right)$ molecules. The variation of the molar ratio between both molecules resulted in significant modulation of the structure of nanoparticle assemblies. The spatial arrangement of nanoparticles revealed the very complex structure of alkyne/methylene terminated mixed SAMs. Alkyne terminal groups could not be only studied by the usual characterization surface techniques such as PM-IRRAS and XPS. Therefore, azido-terminated nanoparticles acted as probing agents to determine the spatial distribution of alkyne groups at the surface of mixed SAMs. This approach was combined with scanning tunneling microscopy (STM) and DFT calculations to get a deeper insight into the structure of mixed SAMs of S-CC and $\mathrm{S}-\mathrm{CH}_{3}$ molecules. Gold substrate topography, chemical affinity of molecules, intermolecular interactions and length of alkyl chains were found to be critical parameters that rule the SAM structure.
\end{abstract}

KEYWORDS: click chemistry, defect mediated replacement, structure, collective properties, thiol molecule, phase segregation, theoretical modeling

\section{INTRODUCTION}

Nanoparticles are very attractive thanks to their tunable physical properties arising from collective behavior. ${ }^{1}$ Addressing the spatial arrangement of nanoparticles immobilized onto a surface allows accessing to an infinite and precise modulation of their physical properties, which are of high interest for applications such as magnetic recording media or magnetic sensors. ${ }^{1}$ It is particularly true for magnetic nanoparticles, the properties of which are directly dependent on magnetostatic coupling resulting from dipolar interactions. ${ }^{2-4}$ Among many assembly techniques, self-assembly driven by chemical interactions onto surfaces is very appealing to address the structure of nanoparticle assemblies. ${ }^{5,6}$ In this case, the assembly is mediated on selective areas by specific interactions between functional groups localized at the surface of both substrate and nanoparticles.

Received: November 27, 2018

Accepted: December 19, 2018

Published: December 19, 2018 


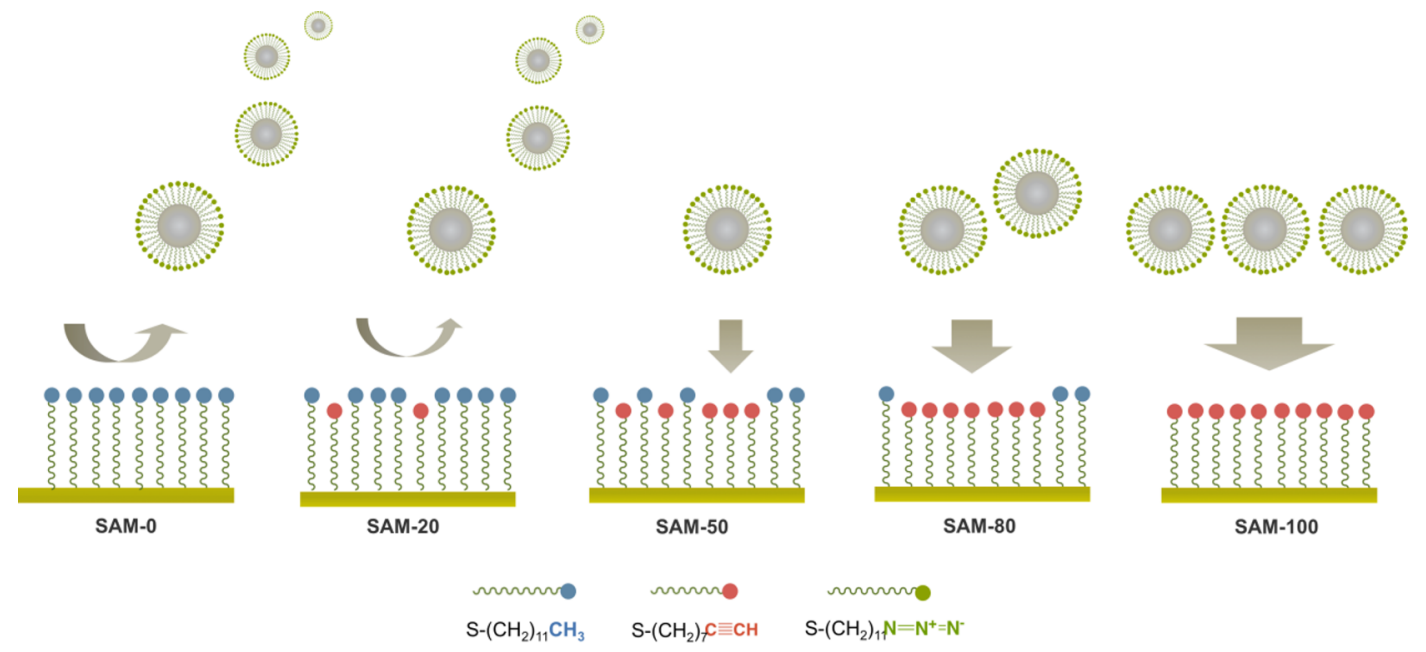

Figure 1. Schematic illustration of the assembly of iron oxide nanoparticles directed by mixed SAMs.

Self-assembled monolayers (SAMs) of $n$-alkanethiolate present the advantage of being an easy way to prepare chemically functionalized gold substrates in ambient conditions. ${ }^{5,7}$ Therefore, many different chemical groups have been used to bring specific functionalities at SAM surfaces. It has resulted in a wide panel of interfacial properties such as hydrophobicity, chemical reactivity, cell adhesion, and molecular recognition. ${ }^{7,8}$ SAMs are also particularly efficient to easily address nanoparticle assembly through multiple $\mathrm{H}$ bonds, ${ }^{7}$ chelates, ${ }^{9-12}$ electrostatic interactions, or covalent bonds. ${ }^{13}$ Recently, a very attractive approach emerged as a new and promising way to prepare complex nanostructures onto surfaces. Click chemistry was initially reported for organic chemistry reactions between molecules ${ }^{14}$ or surface functionalization. ${ }^{15-18}$ Its high reliability, no byproduct formation, mild conditions, and high yields made it very popular. Therefore, it recently became a powerful tool to easily prepare highly stable nanoparticle assemblies onto surfaces through specific chemical reaction.

Some of these click assembling strategies allowed nanoparticle assembling to be addressed with a variety of structures such as isolated nanoparticles, ${ }^{19}$ monolayers, ${ }^{19-21}$ multilayers, ${ }^{22,23}$ or chains. ${ }^{24,25}$ Nevertheless, the control of assemblies at the nanoparticle scale remains critical to fully address the collective properties. In this aim, mixed SAMs which consist of different thiol molecules were developed to modify the surface reactivity at the nanoscale. ${ }^{6,7}$ Mixed SAMs represent a very easy way to introduce different functional groups with tunable spatial arrangement onto substrates. Indeed, the arrangement of adsorbed molecules depends on their respective chemical affinities which allows controlling phase segregation vs homogeneous mixing. ${ }^{6,7}$ Nevertheless, mixed SAMs supported onto gold thin films consist of dynamic systems with complex phase behaviors. Therefore, their structure is ruled by many factors. For instance, structural defect sites such as adsorbate vacancies in the molecular lattice and domain boundaries are critical sites which favor the exchange of molecules from the gold surface with other thiol derivatives in solution. ${ }^{26,27}$ This dynamic feature of SAM structure is particularly interesting with regard to surface functionalization since host molecules can be replaced by guest molecules. $^{28,29}$
Mixed SAMs have been poorly investigated to control the structure of nanoparticle assemblies. ${ }^{30}$ We reported on phase segregation in mixed SAMs of 12-dodecanethiol and 11mercaptoundecanoic acid to prepare sizable domains of iron oxide nanoparticle by controlling chelating interactions. ${ }^{13} \mathrm{We}$ also used iron oxide nanoparticles as probing agents to study the mechanisms pathway of replacement of 12-dodecanethiol by 11 -mercaptoundecanoic at the gold surface. ${ }^{11}$ Finally, we also investigated theoretically the structure of mixed SAMS at the periodic DFT level ${ }^{31}$ and studied its dynamics, very recently. ${ }^{32}$

Herein, we report on the structuring of nanoparticle assembly by adapting the click chemistry approach to mixed SAMs supported on gold thin films which were used to direct nanoparticle assemblies (Figure 1). In contrast to our previous studies which were conducted on single components alkyneterminated SAMs, we took advantage of the ability of molecules to segregate in mixed SAMs in order to modulate the structure of nanoparticle assembly. The surface of mixed SAMs was decorated by alkyne and methylene terminal groups. The former allows immobilizing azido-terminated nanoparticles onto the surface, while the latter acts as a dilution agent and directs the spatial distribution of alkyne groups. We show that the molar ratio between 11-(undec-1-ynyl)thiol (S$\mathrm{CC})$ and 1-dodecanethiol $\left(\mathrm{S}-\mathrm{CH}_{3}\right)$ molecules strongly modulate the structure of nanoparticle assembly. The structure of mixed SAMs is investigated indirectly by the spatial arrangement of nanoparticles. In addition, the spatial arrangement of molecules was studied directly by scanning tunneling microscopy (STM) and density functional (DFT) calculations. Finally, the collective magnetic properties were investigated as a function of the structure of nanoparticle assemblies.

\section{MATERIALS AND METHODS}

Chemicals. 11-(Undec-1-ynyl)thiol (S-CC) and 1-dodecanethiol $\left(\mathrm{S}-\mathrm{CH}_{3}\right)$ were purchased from Aldrich. Tetrahydrofuran (THF) and ethanol were purchased from Carlo Erba and used as received. Triethylamine was obtained from Fluka. Iron stearate was purchased from Strem Chemicals. Oleic acid was purchased from Alfa Aesar.

Synthesis of Azide-Terminated Iron Oxide Nanoparticles (NP@N3). The procedure is fully described in our previous article. ${ }^{19}$ Iron stearate $\left.(\mathrm{Fe} \text { (stearate) })_{2} ; 1.38 \mathrm{~g}, 2.2 \times 10^{-3} \mathrm{~mol}\right)$ was dissolved in octyl ether $(20 \mathrm{~mL})$ with oleic acid $\left(1.24 \mathrm{~g}, 3.3 \times 10^{-3} \mathrm{~mol}\right)$. The mixture was kept at $110^{\circ} \mathrm{C}$ for $30 \mathrm{~min}$ and was brought up to reflux at 
$5{ }^{\circ} \mathrm{C} \cdot \mathrm{min}^{-1}$ without stirring for $120 \mathrm{~min}$ under air. After cooling to room temperature, the black suspension was washed three times with a mixture of chloroform and ethanol (v:v, 1:3) and centrifuged (14000 rpm, $10 \mathrm{~min}$ ). Nanoparticles were easily suspended in tetrahydrofuran (THF). A solution of (12-azidododecyl)phosphonic acid $(\mathrm{AP} 12 \mathrm{~N} 3 ; 15 \mathrm{mg})$ in THF $(10 \mathrm{~mL})$ was added to $10 \mathrm{~mL}$ of the nanoparticle solution and stirred for $48 \mathrm{~h}$ at room temperature. Free molecules were removed by ultrafiltration (using a $30 \mathrm{kDa}$ membrane, Millipore) by washing three times with $20 \mathrm{~mL}$ of THF.

Preparation of Mixed SAMs. Ion sputtered gold substrates were cleaned under $\mathrm{O}_{2} / \mathrm{H}_{2}$ plasma for $2 \mathrm{~min}$ and were soaked in a $10 \mathrm{mM}$ ethanolic solution of thiol derivatives at room temperature for $20 \mathrm{~h}$. Each SAM was then rinsed with copious amounts of pure ethanol and dried under nitrogen stream.

Assembling of Iron Oxide Nanoparticles onto Mixed SAMs. Mixed SAMs were immersed directly after preparation in the suspension of azido-terminated nanoparticles in $\mathrm{THF} /$ triethylamine mixture (v:v, 10:1). After addition of $\mathrm{CuBr}\left(\mathrm{PPh}_{3}\right)_{3}\left(6.5 \mathrm{mg}, 6.7 .10^{-3}\right.$ $\mathrm{mmol}$ ), the reaction was performed under reflux for $48 \mathrm{~h}$. Substrates were then extensively rinsed with THF. They were placed in an ultrasonic bath in THF for $10 \mathrm{~s}$ to remove any physisorbed nanoparticles and finally dried under a nitrogen stream.

\section{CHARACTERIZATION TECHNIQUES}

Transmission electronic microscopy (TEM) was performed by using a TOPCON microscope (model 002B) operating at 200 $\mathrm{kV}$ with a point-to-point resolution of $0.18 \mathrm{~nm}$. Nanoparticle size distribution was calculated from the size measurements of more than 300 nanoparticles from TEM micrographs by using the ImageJ software. Dynamic light scattering (DLS) measurements were performed on the suspension of nanoparticles in tetrahydrofuran, using a nanosize MALVERN (nano ZS) apparatus.

Polarization modulation infrared reflection-absorption spectroscopy (PMIRRAS) was performed on gold substrates after being immersed in thiol solutions, using a IF66S Bruker spectrometer with a liquid nitrogen-cooled mercury cadmium telluride (MCT) detector. Typical data were derived from 2000 scans at a resolution of $1 \mathrm{~cm}^{-1}, 85^{\circ}$ beam angle of incidence, and $74 \mathrm{kHz}$ modulation frequency.

Scanning electronic microscopy (SEM) was performed by using a JEOL 6700 microscope equipped with a field emission gun (SEM-FEG) operating at an accelerating voltage of $3 \mathrm{kV}$.

Atomic force microscopy (AFM) was performed by using an ICON atomic force microscope from Bruker operating with a Nanoscope V controller. All experiments were conducted in air and atmospheric pressures. The images were acquired in standard tapping mode with probe amplitude oscillations around $15 \mathrm{~nm}$. We used probes with a normal stiffness of the order of $10 \mathrm{~N} / \mathrm{m}$ (first normal-resonant mode of about 260 $\mathrm{kHz}$ ). All AFM tips had apex radii around $5 \mathrm{~nm}$ with an upper conical shape of an angle of $25^{\circ}$. These geometrical parameters kept to a minimum the tip convolution effects which can then be precisely evaluated. Collected data were analyzed with Nanotec WSXM software. ${ }^{33}$

Ellipsometry was performed by using a SENpro ellipsometer in a spectral range from 350 to $1050 \mathrm{~nm}$ using a tungsten halogen lamp and spot size of $2 \mathrm{~nm}$.

X-ray photoelectron spectroscopy (XPS) measurements were carried out in an ultrahigh vacuum setup (base pressure $\sim 5 \times 10^{-9}$ mbar) described elsewhere. ${ }^{34}$ A monochromated $\mathrm{Al} \mathrm{K} \alpha \mathrm{X}$-ray source was used as incident radiation (energy resolution better than $0.4 \mathrm{eV}$ ). Prior to individual elemental scans, a survey scan was taken for all the samples to detect all of the elements present. The CASA XPS program with a
Gaussian-Lorentzian mix function and Shirley background subtraction was employed to deconvolute the XP spectra. All binding energies were calibrated to the $\mathrm{Au} 4 \mathrm{f}_{7 / 2}$ peak at 83.8 $\mathrm{eV}$. The sulfur, carbon and gold contents were calculated by $\mathrm{S}$ $2 \mathrm{p}, \mathrm{C} 1 \mathrm{~s}$, and $\mathrm{Au} 4 \mathrm{f}$ core level peaks, properly normalized to the photoemission cross-section and assuming a homogeneous distribution arrangement model. The full width at halfmaximum intensity (fwhm) of the $S 2 p_{3 / 2}$ peak was better than $1 \mathrm{eV}$ as measured by a reference sample under the same spectrometer settings.

Scanning tunneling microscopy (STM) was performed in air and at ambient temperature by using a commercial STM head mounted on a commercial atomic force microscope (Multimode basis with a Nanoscope $\mathrm{V}$ electronic from Bruker). A hand-cut Pt-Ir wire (diameter $=0.25 \mathrm{~mm}$ ) is used as a tip. A preamplificator has allowed measurements at tunnel currents around $1 \mathrm{pA}$ for an applied tip-sample difference of potential around $0.2-1 \mathrm{~V}$, experimental conditions necessary to image the end of the thiol molecules and not the gold substrate. The potential is applied to the sample, and the tip is ground, so the electrons flow from the tip to the sample. STM analysis has been done using gold on mica samples. Gold substrates were prepared by vacuum evaporation of $100 \mathrm{~nm}$ thick gold films onto freshly cleaved mica substrate at a pressure of $10^{-8}$ Torr and a substrate temperature of $600 \mathrm{~K}$. Each sample was then flame annealed at $800 \mathrm{~K}$ for a few seconds and quenched in ultrapure water, leading to (111) textured gold films with terraces $100-200 \mathrm{~nm}$ wide as verified by STM. Afterward the gold substrate follow the mixed SAM deposition procedure.

Magnetic curves were recorded at 300 and $5 \mathrm{~K}$ by applying a magnetic field in the plane of the substrate by using a superconducting quantum interference device (SQUID) magnetometer (Quantum Design MPMS SQUID-VSM dc magnetometer). Magnetization was recorded at 300 and $5 \mathrm{~K}$ by applying a magnetic field from -7 to $+7 \mathrm{~T}$. Magnetization curves were recorded against temperature from 5 to $300 \mathrm{~K}$ under a magnetic field of 75 G. $M(T)$ curves were normalized to the maximum values of the magnetization of $\mathrm{ZFC}$ curve. The magnetic field was applied in the plane of substrates.

\section{THEORETICAL MODEL}

Computational Details. Calculations were performed in the frame of periodic DFT by means of the Vienna ab Initio Simulation Package (VASP 5.2.11). ${ }^{35,36}$ The electron-ion interactions were described by the projector augmented wave (PAW) method, ${ }^{37,38}$ representing the core electrons, as provided in the code libraries. The convergence of the planewave expansion was obtained with a cutoff of $500 \mathrm{eV}$. The generalized gradient approximation (GGA) was used with the functional of Perdew-Burke-Ernzerhof (PBE). ${ }^{38}$ The sampling in the Brillouin zone was performed on a $3 \times 3 \times 1 k$ point mesh.

Since our system involves organic molecules which interact through weak forces, dispersion-corrected DFT was used in all the calculations through the Grimme D3 method ${ }^{39}$ as implemented in VASP 5.4. In this approach, DFT-D3 describes the dispersion interactions between a particle and its neighbors in a given radius, via a simple pairwise force field. This force field is optimized for several popular DFT functionals, especially to the one used here, i.e., PBE. Finally, the dispersion energy $\Delta E_{\mathrm{D} 3}$ is summed to the pure DFT energy $\Delta E_{\mathrm{DFT}}$ : 

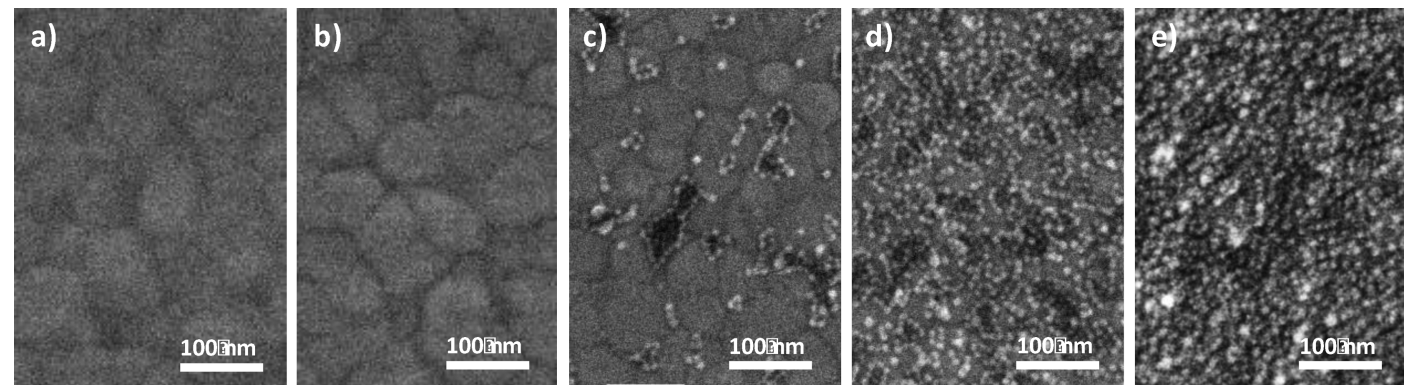

Figure 2. SEM micrographs of mixed SAMs after performing CuAAC "click" reaction in the presence of NP@N $\mathrm{N}_{3}$ (a) SAM-0, (b) SAM-0.2, (c) SAM-0.5, (d) SAM-0.8, and (e) SAM-1.

$$
\Delta E_{\mathrm{ads}}=\Delta E_{\mathrm{DFT}}+\Delta E_{\mathrm{D} 3}
$$

The adsorption (physisorption) or binding (chemisorption) energy is calculated as follows (the terms physi- and chemisorption indicate the presence of an $\mathrm{S}-\mathrm{H}$ group or not, differently from the usual terminology indicating a weak or a strong adsorption):

$$
\Delta E_{\text {ads } / \text { bind }}=E_{\text {thiol } / \text { slab }}-E_{\text {slab }}-E_{\text {thiol }}
$$

From $\Delta E_{\text {bind }}$ one can obtain an approximation for the interchain interaction energy $\Delta E_{\text {int chain }}$ as follows:

$$
\Delta E_{\text {intchain }}=\Delta E_{\text {ads }}-\Delta E_{\text {bind }}
$$

Models. The thiol molecules studied are $\mathrm{H}-\mathrm{S}-\left(\mathrm{CH}_{2}\right)_{11^{-}}$ $\mathrm{CH}_{3}$ and $\mathrm{H}-\mathrm{S}-\left(\mathrm{CH}_{2}\right)_{9}-\mathrm{C} \equiv \mathrm{C}-\mathrm{H}$. The adsorption processes of both thiols on the $\mathrm{Au}(111)$ surface are modeled using slabs containing four Au layers. ${ }^{40}$ The vacuum between subsequent slabs in the infinite three-dimensional representation was fixed to $25 \AA$. The unit cell employed to study the SAM structures is $(2 \sqrt{ } 3 \times 2 \sqrt{ } 3) R 30^{\circ}$, which is equivalent to the $c(4 \times 2)$ unit cell, with $48 \mathrm{Au}$ atoms. The unit cell parameter (4.177 $\AA$, compared with $4.078 \AA$ experimentally) of $\mathrm{Au}$ is obtained after optimization of the bulk at the same level of calculation as the thiol SAM. It should be noted that only a perfect defect free $\mathrm{Au}(111)$ surface has been considered.

\section{NANOPARTICLE SYNTHESIS AND ASSEMBLY}

The assembly of iron oxide nanoparticles was achieved onto gold substrates by performing the copper(I) catalyzed alkyneazide cycloaddition (CuAAC) "click" reaction. ${ }^{19}$ The specific reaction between azide-terminated nanoparticles $\left(\mathrm{NP} @ \mathrm{~N}_{3}\right)$ and alkyne-terminated gold substrate (SAM-CC) resulted in the irreversible formation of multicovalent triazol bonds. This strategy contributes to the preparation of highly stable nanoparticle assemblies onto substrates. Iron oxide nanoparticles were prepared by the thermal decomposition method and were postfunctionalized by 12-azidododecylphosphonic acid (AP12N3) as we have reported earlier. ${ }^{19}$ This strategy allows the preparation a highly stable suspension in THF by avoiding any aggregates (Supporting Information), which is highly critical to address precisely the structure of nanoparticle assemblies in the frame of the bottom-up approach. Azidoterminated nanoparticles $\left(\mathrm{NP} @ \mathrm{~N}_{3}\right)$ were featured by narrow size distribution centered at $11.5 \pm 1.1 \mathrm{~nm}$ and homogeneous spheric shape. Gold substrates were functionalized by a mixture of 11-(undec-1-ynyl)thiol (S-CC) and 12-dodecanethiol $\left(\mathrm{S}-\mathrm{CH}_{3}\right)$ molecules. The density and the spatial arrangement of alkyne and methylene terminal groups at SAM surfaces were modulated by preparing $10 \mathrm{mM}$ ethanolic solutions of S-CC/S- $\mathrm{CH}_{3}$ with molar ratios of $0,0.2,0.5,0.8$, and 1 . Gold substrates were dipped in these solutions for $20 \mathrm{~h}$ at room temperature to allow stabilization. Molecules selfassembled onto the gold surface through van der Waals interactions which favor the specific localization of alkyne and methylene terminal groups at the SAM surface. The alkyne groups acted as active groups toward nanoparticle assembly by click chemistry, while the methylene groups are inactive and control indirectly the spatial arrangement of nanoparticles. The resulting functionalized substrates were named according to $S$ $\mathrm{CC} / \mathrm{S}-\mathrm{CH}_{3}$ molar ratio: SAM-0, SAM-0.2, SAM-0.5, SAM-0.8 and SAM-1.

SEM micrographs show each SAM after performing CuAAC reaction, e.g., after dipping in THF suspension of $\mathrm{NP} @ \mathrm{~N}_{3}(0.5$ $\mathrm{mg} / \mathrm{mL}$ ) for $48 \mathrm{~h}$ at $60^{\circ} \mathrm{C}$ (Figure 2). SAM-0 does not show any nanoparticles which agree with the presence of terminal $\mathrm{CH}_{3}$ groups at the SAM surface. The SEM micrograph shows the gold grains underneath the self-assembled monolayer of organic molecules. In contrast, the observation of nanoparticles corresponds to the presence of alkyne groups at the SAM surface. The nanoparticle density $\left(3820 \pm 20 \mathrm{NPs} / \mu \mathrm{m}^{2}\right)$ is the highest on SAM-1 and is very close to the maximum theoretical value $\left(4770 \mathrm{NPs} / \mu \mathrm{m}^{2}\right)$. This result agrees with the fact that SAM-1 only consists of S-CC molecules of which alkyne groups fully cover the surface. Both samples clearly show the high stability of SAMs upon the assembly process. Indeed, the desorption of $\mathrm{S}-\mathrm{CH}_{3}$ would have led to the presence of nanoparticles through the interaction of azide groups with the gold thin film. S-CC molecules also remain adsorbed onto a gold thin film as we reported previously in similar conditions. ${ }^{20}$ Furthermore, the nanoparticle density is intermediate at the surface of SAM-0.5 $\left(210 \pm 50 \mathrm{NPs} / \mu \mathrm{m}^{2}\right)$ and SAM-0.8 $\left(2620 \pm 30 \mathrm{NPs} / \mu \mathrm{m}^{2}\right)$, which is in agreement with lower $\mathrm{S}-\mathrm{CC} / \mathrm{S}-\mathrm{CH}_{3}$ molar ratios used for solutions. It is worth noting that the nanoparticle density does not increase linearly with $\mathrm{S}-\mathrm{CC} / \mathrm{S}-\mathrm{CH}_{3}$ solution ratios and that the spatial arrangement of nanoparticles is not homogeneous. SAM-0.2 displays very few isolated nanoparticles and looks similar to SAM-0. SAM-0.5 displays a higher number of nanoparticles, which tend to assemble in lines on areas mostly corresponding to gold grain junctions and from which $2 \mathrm{D}$ assemblies seem to grow. SAM-0.8 shows larger 2D assemblies of nanoparticles (up to $100 \mathrm{~nm}$ ) which coexist with small uncovered areas. Finally, as reported recently, ${ }^{41}$ nanoparticles assembled by click chemistry are all expected to contain azide groups at their surface, which may be suitable for postfunctionalization by biomolecules for instance. 

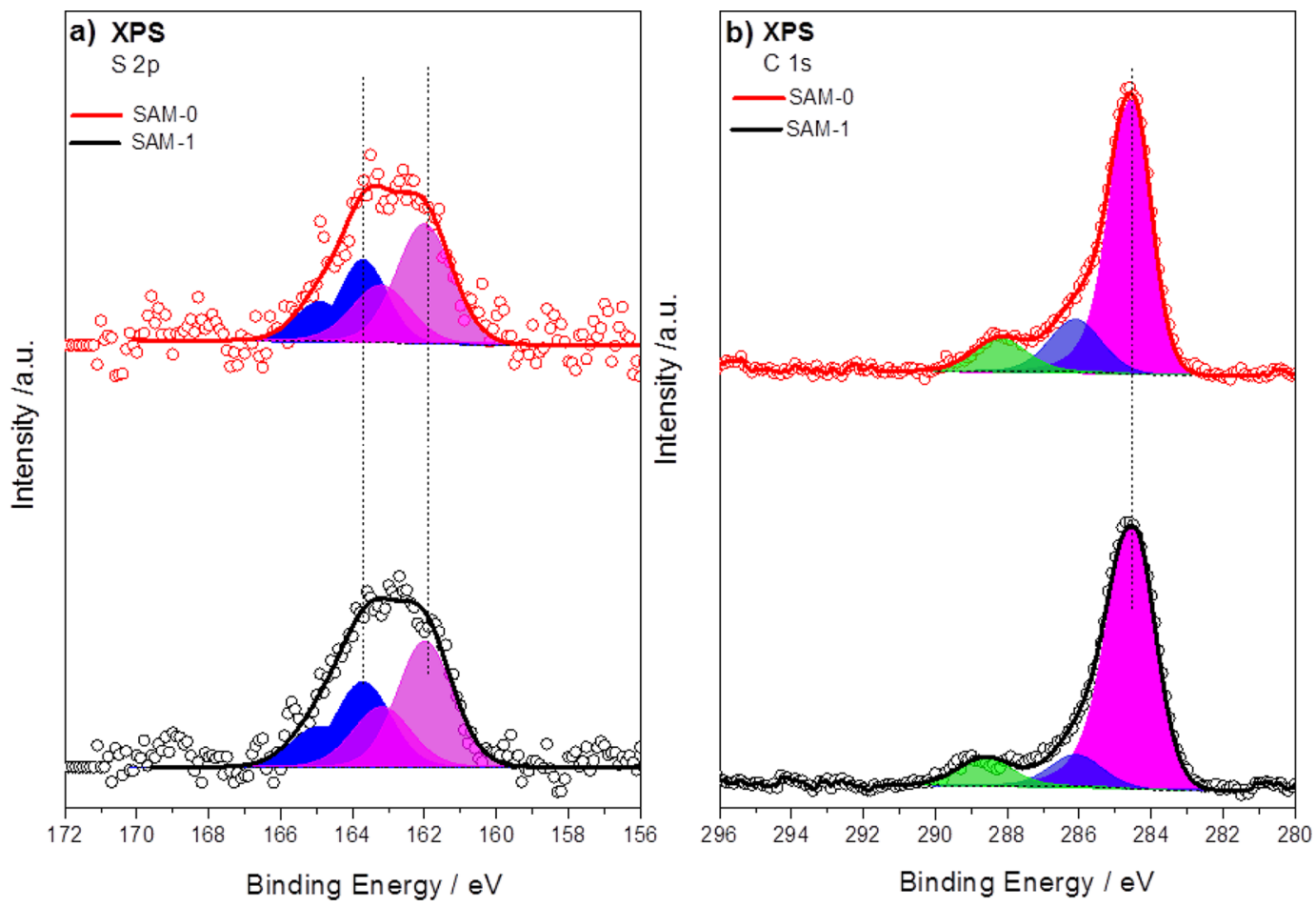

Figure 3. XPS spectra of SAM-0 and SAM-1: (a) S 2p signal and (b) C 1s signal.

\section{SAM CHARACTERIZATION}

SAMs were deeply characterized by several characterization techniques. Ellipsometry was used first for preliminary measurements in order to demonstrate that gold substrates were covered by an organic layer with a thickness below $2 \mathrm{~nm}$, whatever the composition of SAMs. AFM height images of the gold substrate, profile cross-sections, and the measured roughness of $1.6 \mathrm{~nm}$ showed it consists of a typical grain structure resulting in terraces separated by junctions.

The chemical compositions of SAM-0 and SAM-1 were also investigated by XPS (Figure 3). The survey scan of SAM-1 is dominated by the photoelectron peaks of $\mathrm{Au}, \mathrm{O}$, and $\mathrm{C}$ (see the Supporting Information (SI)). High-resolution spectra showed that the $S 2 \mathrm{p}$ core level spectrum could be deconvoluted in two doublets, according to the literature. ${ }^{42}$ The doublet at $161.9 \mathrm{eV}$ (magenta peaks) with the highest intensity is attributed to the S-Au bond. The second doublet at higher BEs $(163.9 \mathrm{eV})$ is much weaker and is related to S$\mathrm{H}$ or $\mathrm{S}-\mathrm{C}$ groups corresponding to some unbound thiol derivatives at the SAM surface which represent $30 \% .{ }^{43}$ One may also observe a very noisy peak at $169 \mathrm{eV}$ in the SAM-1 spectrum which may be attributed to a very low amount of oxidized thiol. ${ }^{44}$ The main contribution in the $\mathrm{C} 1 \mathrm{~s}$ peak at $284.5 \mathrm{eV}$ corresponds to single bonded carbons (C-C) of alkylene chains. ${ }^{45}$ The two components at higher binding energies $(286.0$ and $288.1 \mathrm{eV}$ ) are induced by carbons bonded to oxygen (mainly $\mathrm{C}-\mathrm{O}, \mathrm{C}=\mathrm{O}$, and $\mathrm{O}-\mathrm{C}=\mathrm{O}$ species) as it is also confirmed from the $\mathrm{O} 1 \mathrm{~s}$ peak (not shown). ${ }^{46}$ The presence of these species might be provoked by $\mathrm{CO}_{2}$ adsorption over the SAM surface; ${ }^{46}$ however, one cannot exclude the possibility that the high binding energy peak is partially induced by the oxidation of $\mathrm{S}-\mathrm{CH}_{3}$ and $\mathrm{S}-\mathrm{CC}$ molecules. Unfortunately, the contribution of alkyne groups in the $\mathrm{C} 1 \mathrm{~s}$ spectra cannot be distinguished since these species, with binding energies around $285 \mathrm{eV},{ }^{47}$ overlap with the main
$\mathrm{C} 1 \mathrm{~s}$ peaks due to $\mathrm{C}-\mathrm{C}$ bonds. The calculated $\mathrm{S} / \mathrm{C}$ ratio was found to be $0.08 \pm 0.01$ and was the same for both samples, in close agreement with the stoichiometries of S-CC and $\mathrm{S}-\mathrm{CH}_{3}$ molecules. In addition, the similar $\mathrm{S} / \mathrm{Au}$ ratio of $0.09 \pm 0.01$ for both SAM-0 and SAM-1 is indicative of the high density and tight packing of both thiol molecules onto the gold substrates. $^{48,49}$

PM-IRRAS spectra recorded for SAM-0 and SAM-1 (Figure 4) showed typical signals of alkylene chains. $\nu_{\mathrm{as}}\left(\mathrm{CH}_{2}\right)$ and $\nu_{\mathrm{s}}\left(\mathrm{CH}_{2}\right)$ bands were centered at 2918 and $2849 \mathrm{~cm}^{-1}$ for SAM-0 and at 2925 and $2854 \mathrm{~cm}^{-1}$ for SAM-1. These positions suggest ordered and close-packed alkylene chains into a primarily all-trans configuration for $\mathrm{S}-\mathrm{CH} 3$ molecules, while S-CC molecules are slightly disordered. ${ }^{50}$ Bands at 2963

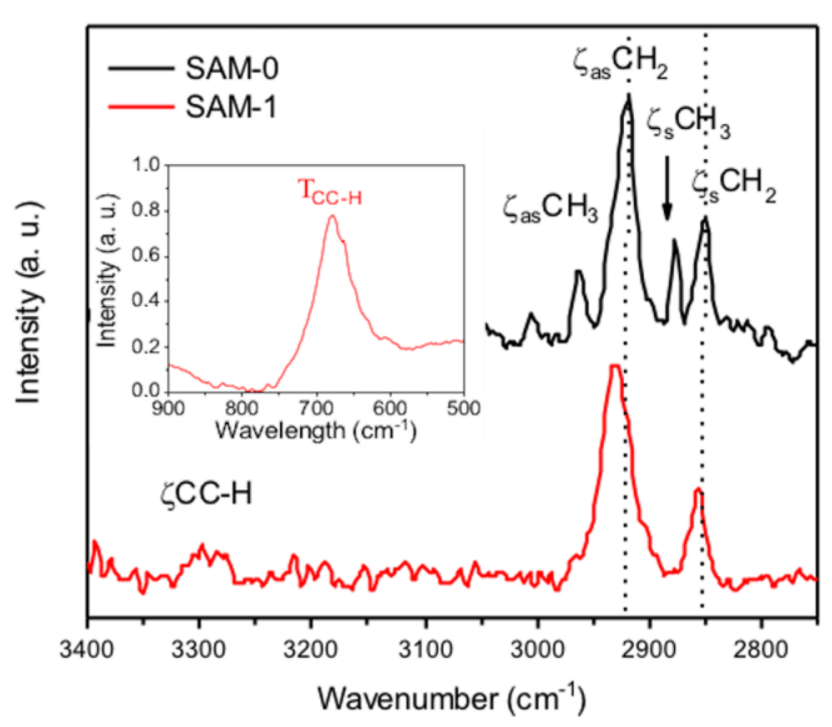

Figure 4. PM-IRRAS spectra of SAM-0 and SAM-1. 

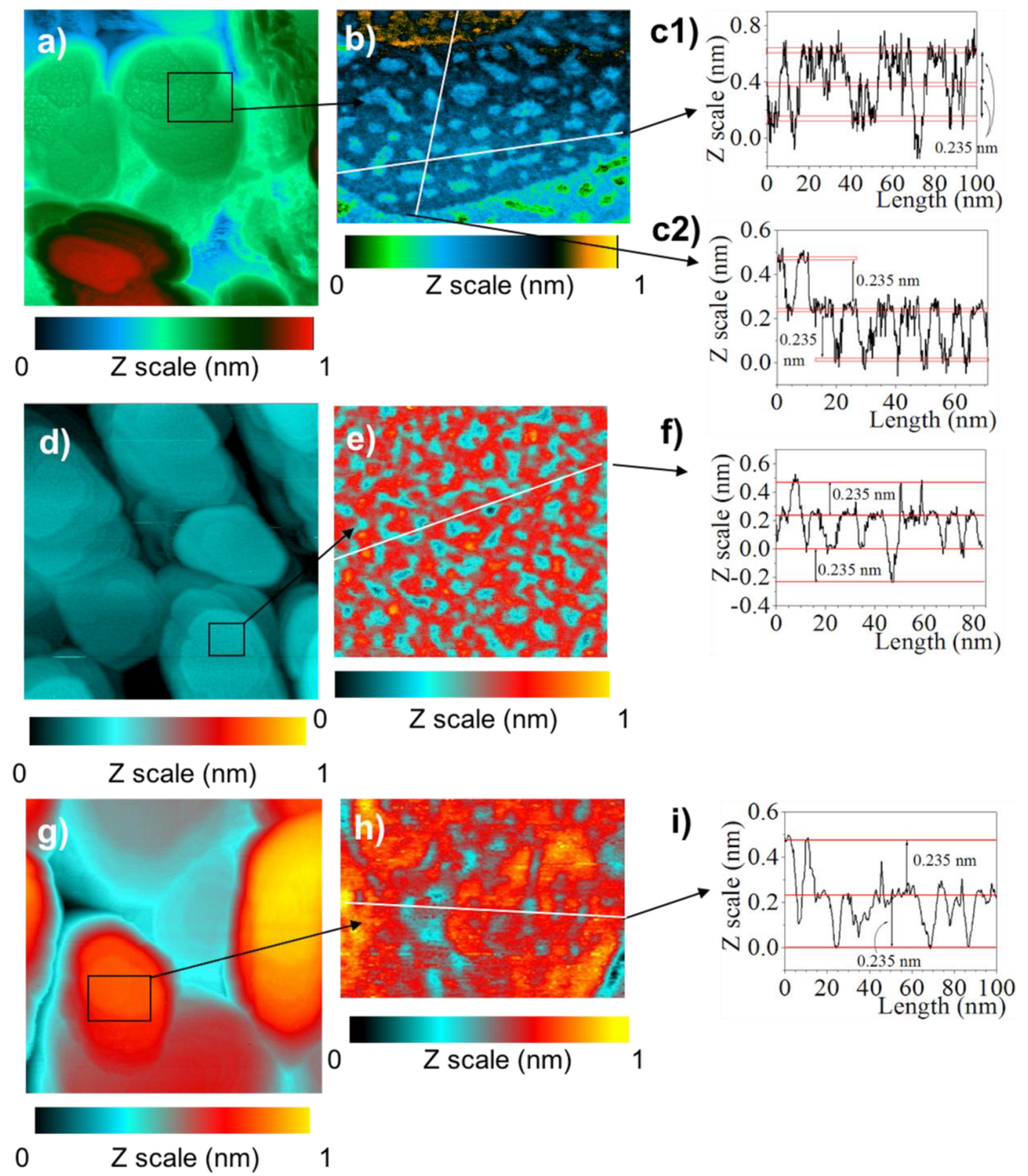

Figure 5. STM images of mixed SAMs on a $\mathrm{Au}(111)$ surface. SAM-0: (a) $500 \times 500 \mathrm{~nm}$ image; (b) $100 \times 80 \mathrm{~nm}$ image; (c1 and c2) sections along the white lines. SAM-0.5: (d) $500 \times 500 \mathrm{~nm}$ image; (e) $80 \times 70 \mathrm{~nm}$ image; (f) section along the white line. SAM-1: $(\mathrm{g}) 500 \times 500 \mathrm{~nm}$ image; (h) $80 \times 70 \mathrm{~nm}$ image; (i) section along the white line. All images have been taken at a tunneling current of 2 pA and a tip bias of $1 \mathrm{~V}$.

$\mathrm{cm}^{-1}(\nu \mathrm{as})$ and $2878 \mathrm{~cm}^{-1}(\nu \mathrm{s})$ corresponding to $\mathrm{CH}_{3}$ stretching are only observed for SAM-0 and correspond to the terminal methylene groups. The broad band at about 3300 $\mathrm{cm}^{-1}$ observed for SAM-1 corresponds to the $\nu(\mathrm{CC}-\mathrm{H})$ vibration. ${ }^{51}$ It is confirmed by $\delta(\mathrm{CC}-\mathrm{H})$ vibration at 680 $\mathrm{cm}^{-1}$. This band is usually difficult to observe because the absorption coefficient is very low due to the vanishing small transition dipole moment of the CC triple bond. ${ }^{20}$

The structure of alkyne/methylene terminated mixed SAMs was investigated directly by performing STM in order to get additional information (Figure 5). As shown by the $500 \mathrm{~nm} \times$ $500 \mathrm{~nm}$ sized images noted A, D and G, STM confirms that gold substrates were covered by an organic layer. In fact, $\mathrm{Au}$ (111) terraces and also grains boundaries present "holes" domains randomly distributed over the entire surface. This result is typical for SAMs on gold surfaces as discussed in the literature. $^{6}$ As shown on the zoomed image $\mathrm{B}$, and the crosssections $\mathrm{C} 1$ and $\mathrm{C} 2$, these holes are substrate vacancies consisting of one atomic layer deep of gold. Monoatomic step edges (C2), where one atomic layer of gold separates the gold terraces from each other with a height difference of $\sim 0.235$ $\mathrm{nm}$, are present. These vacancies have been formed during the adsorption process. The involved mechanism is based on the fact that the $\mathrm{Au}-\mathrm{S}$ bond is strong enough to weaken proximal $\mathrm{Au}-\mathrm{Au}$ bonds in the lattice beneath the assembly. Gold desorbed in the solution and the vacancies coalesce into domains. The process occurs for both molecules since it is related to the thiol end group.

Second, since we do not observe significant height changes other than the presence of gold vacancies domains as a function of the SAMs solution composition, we can conclude that our mixed SAMs do not segregate in air at room 
temperature. That is coherent with previous studies ${ }^{6}$ showing that molecules of similar enough composition do not phase separate if formed at room temperature from the same solution. The likelihood of preferential exchange is decreased, as the energies of salvation and exchange will be similar between the two adsorbates. In fact, Monte Carlo simulations ${ }^{52}$ predict phase segregation when two components have a chain length difference of seven or eight carbon atoms and experimentally $^{27}$ phase segregation was observed at room temperature when the chain length difference is greater than four carbons, which is not our case. If the chain length difference is only one or two carbon atoms, it is hard to detect the difference in a mixed SAMs monolayer with a low-current STM. $^{53}$ It is why, on the cross-sections $\mathrm{C} 1, \mathrm{C} 2, \mathrm{~F}$, and I, we observe a rather "homogeneous" height distribution around the height changes of $0.235 \mathrm{~nm}$. The small height fluctuations are due to the fact that the molecules stand up at our high surface coverage with the hydrocarbon tails tilting approximately $30^{\circ}$ from the surface normal and nominally in the all-trans configuration (confirmed by PM-IRRAS) so as to maximize van der Waals interactions (see simulation below). Since the tunneling current just reflects the surface Fermi level, STM cannot distinguish the true height difference between two chains separated by one carbon atom. In our case, it is highly probable that small angle fluctuations conduct to small height changes when the tip scans over these tightly packed structures.

Third, STM measurements show that $\mathrm{S}-\mathrm{CH}_{3}$ molecules desorbed much more easily from the gold surface than S-CC molecules. With the flooding procedure of the freely available WSxM software, ${ }^{33}$ we determine the percentage of the surface covered by holes domains using images $\mathrm{B}, \mathrm{E}$, and $\mathrm{H}$ as input (not shown). It decreases from around $30 \%$ for the SAM-0 samples to $20 \%$ for SAM-1 with an intermediate value of $22-$ $23 \%$ for SAM-0.5. Since the holes are related to the desorption ability of molecules connected to a gold atom, we conclude that $\mathrm{S}-\mathrm{CH}_{3}$ molecules desorbed easier than S-CC molecules, which is coherent with the computational results.

\section{COMPUTATIONAL RESULTS}

In order to study the stability of the S-CC/S- $\mathrm{CH}_{3}$ mixture in SAMs, a series of models representing each different S-CC/S$\mathrm{CH}_{3}$ molar ratio of mixed SAMs were considered. The mean adsorption energy per thiol chain $\left(\Delta E_{\text {ads }}\right)$ was calculated for perfect mixtures of S-CC and $\mathrm{S}-\mathrm{CH}_{3}$ as follows:

$$
\begin{aligned}
\Delta E_{\mathrm{ads}}= & \frac{1}{4}[E(2 \times 2 \text { system })-E(\text { surface slab }) \\
& \left.-n E\left({ }^{\circ} \mathrm{S}-\mathrm{CC}\right)-(4-n) E\left({ }^{\circ} \mathrm{S}-\mathrm{CCH} 3\right)\right]
\end{aligned}
$$

with $n=0,1,2,3$, or 4 corresponding to the number of S-CC molecules per unit cell, $E(2 \times 2$ system $)$ the energy of the SAM adsorbed on the $\mathrm{Au}(111)$ surface, $E$ (surface slab) the energy of the bare $\mathrm{Au}(111)$ slab, and $E\left(\mathrm{CC}-\left({ }^{\circ} \mathrm{S}-\mathrm{CC}\right)\right.$ and $E\left({ }^{\circ} \mathrm{S}-\mathrm{CH}_{3}\right)$ the energies of an isolated alkyne and methylene thiol radicals, respectively.

Adsorption energy $\left(\Delta_{\mathrm{ads}}\right)$ values including the dispersion interaction energy are much larger than without correction (Table 1). This result confirms the importance of dispersion interactions in long alkyl chain thiol derivatives. Indeed, the dispersion interactions represent $60 \%$ (eq 3) of the total adsorption energy, and $30 \%$ and $40 \%$ of the intramolecular interaction energy for the $\mathrm{S}-\mathrm{CH}_{3}$ and $68 \%$ for the S-CC thiol
Table 1. Adsorption Energy $\left(\Delta E_{\text {ads }}\right)$ per Thiol Chain Calculated for Each S-CC/S- $\mathrm{CH}_{3}$ Molar Ratio by Taking into Account the Dispersion Interaction Energy (PBED3 $)^{39}$ or Not (PBE) According to Equation 1

\begin{tabular}{ccc} 
S-CC/S-CH $\mathrm{CH}_{3}$ molar ratio & $\mathrm{PBE}-\mathrm{D} 3(\mathrm{eV})$ & $\mathrm{PBE}(\mathrm{eV})$ \\
$(\%)$ & $\left(\Delta E_{\mathrm{DFT}}+\Delta E_{\mathrm{D} 3}\right)$ & $\left(\Delta E_{\mathrm{DFT}}\right)$ \\
$100 / 0$ & -3.60 & -1.13 \\
$75 / 25$ & -3.47 & -1.30 \\
$50 / 50$ & -3.31 & -1.20 \\
$25 / 75$ & -3.24 & -1.29 \\
$0 / 100$ & -3.17 & -1.27 \\
\hline
\end{tabular}

SAM, respectively. The latter has been calculated using the $\mathrm{Au}-\mathrm{S}$ binding energy of $2.60 \mathrm{eV}$ of alkyl chain thiols. ${ }^{54}$

Adsorption energy $\left(\Delta E_{\mathrm{ads}}\right)$ values also clearly show that interactions between $\mathrm{S}$-CC chains are more favorable than between $\mathrm{S}-\mathrm{CH}_{3}$ chains. Although the alkyl chain is shorter in $\mathrm{S}$ $\mathrm{CC}$ than in $\mathrm{S}-\mathrm{CH}_{3}\left(9 \mathrm{CH}_{2}\right.$ against $\left.11 \mathrm{CH}_{2}\right)$, van der Waals interactions are compensated by dipolar interactions between alkyne head groups. It is confirmed by $\Delta E_{\text {ads }}$-corrected and uncorrected values, which show that the dispersion interaction energy predominates between chains of $\mathrm{S}-\mathrm{CH}_{3}$ molecules.

Mean values of adsorption energy $\left(\Delta E_{\text {ads,mean }}\right)$ were also calculated for segregated mixtures by considering pure phases. For instance, $\Delta E_{\text {ads,mean }}=\left(\Delta E_{\text {ads,4alkyl }}+\Delta E_{\text {ads,4alkyne }}\right) / 4=-3.38$ $\mathrm{eV}$ for SAM-0.5. This value is further used as a reference value in order to quantify the stabilization of the SAM mixture. ${ }^{30,54,55}$

$\Delta E_{\text {ads }}$ is the lowest for all segregated mixtures whatever the $\mathrm{S}-\mathrm{CC} / \mathrm{S}-\mathrm{CH}_{3}$ molar ratio (Figure 6). It shows that

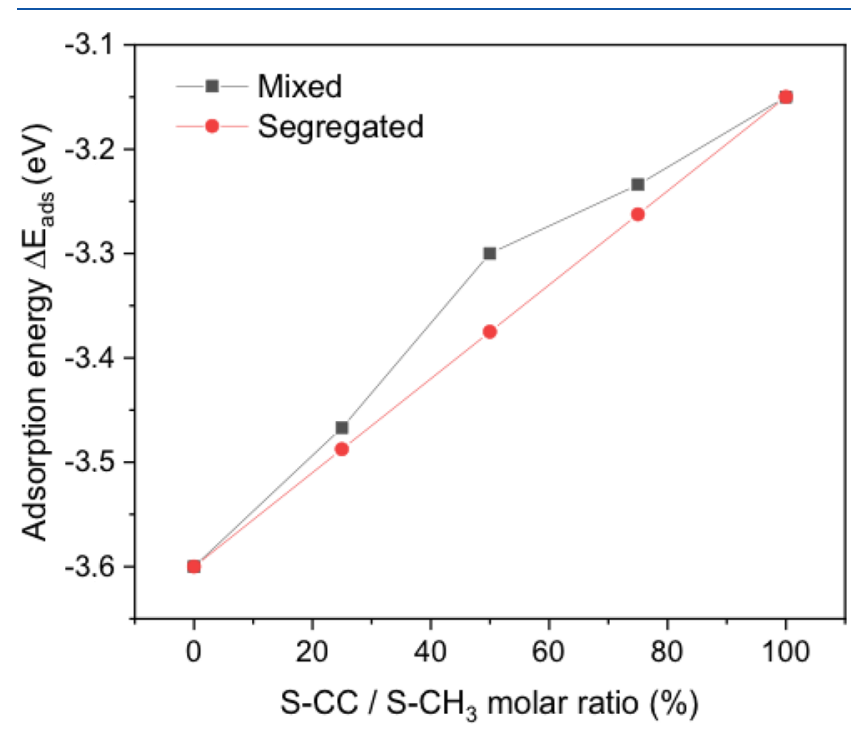

Figure 6. Adsorption energy calculated for mixed SAMs consisting of different mixtures of S-CC and $\mathrm{S}-\mathrm{CH}_{3}$ molecules (mixed), compared with the mean adsorption energy calculated from the pure faces (segregated).

intermolecular interactions are thermodynamically favored in segregated mixtures. Nevertheless, small variations being observed (below $1 \mathrm{eV}$ ), we expect both segregated and perfect mixtures to coexist thermodynamically. These results agree with studies which usually report on perfectly mixed SAMs (no segregation) prepared from mixtures of $n$-alkyl thiols presenting small differences between alkyl chain length and terminal groups. ${ }^{5}$ This finding does not include entropic 
considerations to stabilization/formation, which are expected to be of similar magnitude for all SAMs because of the similar physicochemical properties of both thiol derivatives. ${ }^{30,32,54}$

Furthermore, the binding energy $(2.6 \mathrm{eV})$ was calculated to be constant throughout the mixture series. This result agrees with our earlier findings, stating that the $\mathrm{Au}-\mathrm{S}$ binding energy is expected to be related to the sulfur hybridization. ${ }^{30,32,54}$ Concerning the effect of the thiol adsorption on the $\mathrm{Au}(111)$ surface, a precursor state for the formation of an adatom can be seen (Figure 7). STM measurements and theoretical

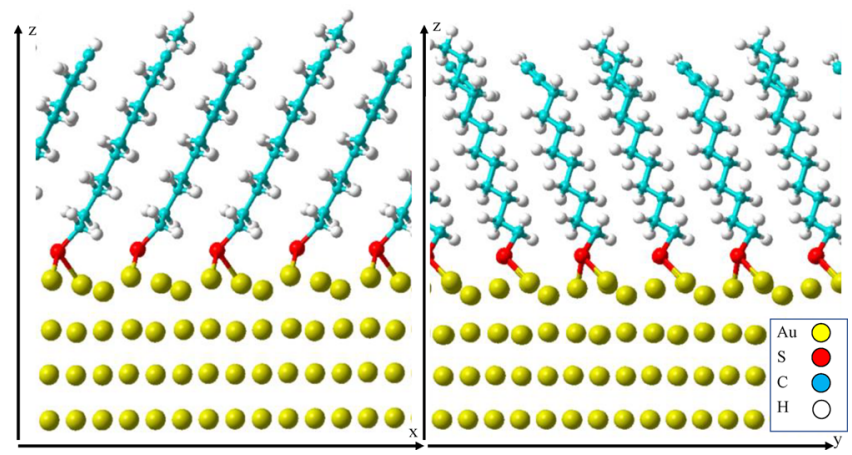

Figure 7. Optimized geometry of the SAM- 0.75 consisting of alternative $\mathrm{S}-\mathrm{CC}$ and $\mathrm{S}-\mathrm{CH}_{3}$ molecules. The top two $\mathrm{Au}(111)$ layers (only shown here) of four used in the unit cell present a reconstruction/reorganization.

calculations showed that the S-CC assembly is more stable than $\mathrm{S}-\mathrm{CH}_{3}$ assembly. Although van der Waals interactions between alkyl chains are stronger for the former, interactions between alkyne head groups in the latter predominate.

\section{MAGNETIC MEASUREMENTS}

The magnetic properties of nanoparticle assemblies have been studied as a function of their structure controlled by SAM-0.5, SAM-0.8, and SAM-1 (Figure 8). Magnetization curves recorded against a magnetic field are representative of the superparamagnetic behavior at $300 \mathrm{~K}$ and ferrimagnetic behavior at $5 \mathrm{~K}$ as we already observed for $\mathrm{Fe}_{3-\delta} \mathrm{O}_{4}$ nanoparticles with similar size. ${ }^{56}$ These results agree with nanoparticles which consist of a single magnetic domain which is blocked at low temperature thanks to magnetic anisotropy energy. In contrast, by increasing temperature, thermal energy becomes the highest, which results in the oscillation of magnetic moments and corresponds to superparamagnetic behavior. Hysteresis cycles at $5 \mathrm{~K}$ display similar coercive fields
(300-400 Oe) for all samples, which agree with our previous studies. ${ }^{19,57}$

Temperature dependent magnetization curves were also very similar. Maxima recorded for ZFC curves can be assimilated to the blocking temperature $\left(T_{\mathrm{B}}\right)$ at which the transition between ferrimagnetic and superparamagnetic behaviors happens. $T_{B}$ being highly sensitive to dipolar interactions, it shows that the increase in nanoparticle density does not influence the magnetic anisotropy energy. Although nanoparticle domains became larger, they reached a critical size onto SAM-0.5. Nanoparticles being tightly packed in all samples, their environment is very similar, so that dipolar interactions occur. These results are confirmed by the plateau observed below $T_{\mathrm{B}}$ in FC curves, which correspond to strong dipolar interactions between nanoparticles, whatever the SAM structure.

\section{DISCUSSION}

Investigation on the Structure of Alkyne-Terminated Mixed SAMs. Alkyne groups are difficult to characterize at the SAM surface because no signal could be observed by XPS and PM-IRRAS due to low sensitivity. ${ }^{51}$ Therefore, these techniques are not suitable for the characterization of alkyne terminal groups at the surface of mixed SAMs. It has been reported that this issue could be circumvented by using probing agents such as an azide-functional molecule containing an infrared active label to detect indirectly alkyne groups. ${ }^{58}$ In this study, we took advantage of azide-terminated nanoparticles as probing agents.

Since nanoparticles can only be immobilized onto areas terminated by alkyne groups, they offer the possibility to map indirectly their spatial arrangement at the surface of mixed SAMs. Therefore, the spatial arrangement of nanoparticles clearly shows that the S-CC/S- $\mathrm{CH}_{3}$ molar ratio in solution modulated the composition of mixed SAMs. SEM micrographs gave first insights on the amount and distribution of alkyne groups at the SAM surface, which were completed by STM measurements and theoretical calculations.

First of all, the nanoparticle density onto mixed SAMs does not systematically reflect the molar ratio of S-CC and $\mathrm{S}_{-} \mathrm{CH}_{3}$ in solution. The absence of nanoparticles on SAM-0.2 is unexpected and may correspond to the absence of alkyne groups at the SAM surface. However, our computational model showed that $\mathrm{S}-\mathrm{CC}$ and $\mathrm{S}-\mathrm{CH}_{3}$ molecules are well mixed in SAM-0.2. Nevertheless, the shorter alkyl chain of S-CC (9 carbons) molecules than $\mathrm{S}^{-\mathrm{CH}_{3}}$ molecules (11 carbons) may render difficult the accessibility of terminal alkyne groups to
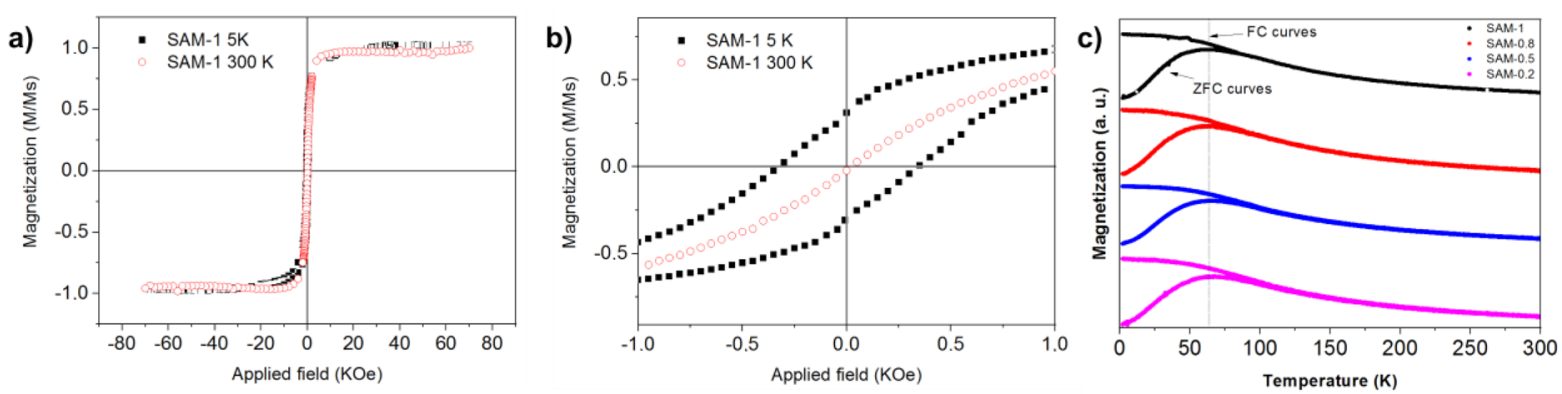

Figure 8. Magnetic measurements of mixed SAMs containing nanoparticles: (a, b) M(H) curves of SAM-1 recorded at $300 \mathrm{~K}$ (both curves overlap) and $5 \mathrm{~K}$; (b) same curves in panel a at a lower magnetic field; (c) $M(T)$ zero field cooled (ZFC) and field cooled (FC) curves recorded for SAM-0.5, SAM-0.8, and SAM-1. 
react with azide groups at nanoparticle surface. These results agree with the non-observation of nanoparticles on SAM-0.2 and large uncovered areas on SAM-0.5. Therefore, uncovered areas at the SAM- 0.5 surface may also consist of $\mathrm{CH}_{3}$ groups perfectly mixed with alkyne groups, which may be in rather large amount but are not accessible.

Second, $n$-alkyl thiol monolayers are a highly dynamic system which is featured by exchange of thiol derivatives from the gold substrate with molecules in solution. STM measurements have shown that $\mathrm{S}-\mathrm{CH}_{3}$ molecules desorbed much more easily from the gold surface than S-CC molecules. This result agrees with theoretical modeling which demonstrated that the most stable system was SAM-1. It is commonly admitted that longer alkyl chains favor stronger intermolecular interactions (van der Waals, hydrophobic, and so on) which improve the stability of SAMs and slow the desorption of thiol derivatives. ${ }^{7}$ In this study, S-CC molecules display the shortest alkyl chain, but interactions between alkyne groups induce significant dipolar moments at the SAM surface which contribute to enhance the stability of adsorbed S-CC molecules.

Third, the spatial arrangement of $\mathrm{S}-\mathrm{CC}$ and $\mathrm{S}-\mathrm{CH}_{3}$ molecules also depends on the topography of gold substrates which consist OF gold grain, i.e., terraces separated by junctions. ${ }^{13}$ Indeed, grain junctions favor topologically the interaction between SAM and nanoparticles. However, they can be assimilated as defect sites which favor rapid desorption/ adsorption process of molecules during equilibration times (20 $\mathrm{h}$ in our case). Therefore, according to our computational calculations (higher stability of S-CC assembly) and STM measurements (greater desorption of $\mathrm{S}-\mathrm{CH}_{3}$ ), S-CC molecules are expected to be preferentially localized at the grain junction.

Fourth, such a defect mediated exchange of $\mathrm{S}-\mathrm{CH}_{3}$ by $\mathrm{S}-\mathrm{CC}$ molecules was confirmed by immersing SAM-0 (pure SAM of $\left.\mathrm{S}-\mathrm{CH}_{3}\right)$ in a $\mathrm{S}-\mathrm{CC}$ ethanolic solution $(10 \mathrm{mM})$ for $24 \mathrm{~h}$ at room temperature (Figure 9a). The new SAM was fully
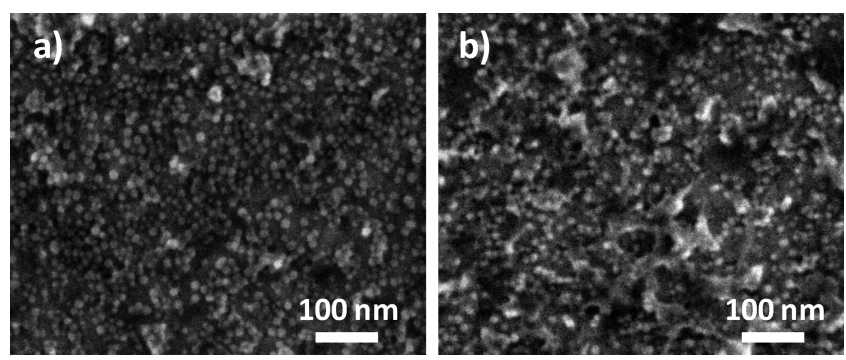

Figure 9. Click chemistry reaction performed after (a) immersion of a SAM-0 in an ethanolic solution of S-CC and (b) immersion of a SAM-1 in an ethanolic solution of $\mathrm{S}_{-} \mathrm{CH}_{3}$.

covered by nanoparticles after performing click reaction, which demonstrates that $\mathrm{S}-\mathrm{CH}_{3}$ molecules were replaced by $\mathrm{S}-\mathrm{CC}$ molecules. The opposite experiment which consisted of dipping a SAM-1 in a $\mathrm{S}-\mathrm{CH}_{3}$ solution before performing click reaction also showed the full coverage of SAM by nanoparticles (Figure 9b). These results confirmed the better stability of the S-CC assembly than the $\mathrm{S}-\mathrm{CH}_{3}$ one deduced from STM and theoretical data.

Nevertheless, the absence of nanoparticles at the surface of SAM- 0.2 shows that both stronger interactions between S-CC molecules and topology of gold substrate are not sufficient to produce large enough areas of $\mathrm{CC}$ and to counterbalance shorter alkyl chains and homogeneous mixing with $\mathrm{S}-\mathrm{CH}_{3}$ molecules. A critical S-CC/S- $\mathrm{CH}_{3}$ molar ratio has to be reached to allow nanoparticles immobilization onto mixed SAMs. Indeed, the critical number of alkyne groups (i.e., S-CC molecules) per surface unit which is necessary to immobilize each nanoparticle at the SAM surface remains an open question. Given the size of iron oxide nanoparticles $(11.5 \mathrm{~nm})$, we estimated that the surface contact between each nanoparticle and the SAM supported by the gold substrate is about $8 \mathrm{~nm}^{2}$. Therefore, the surface occupied by a S-CC molecule being about $20 \AA^{2}$, we expect a maximum of 40 molecules which may interact with nanoparticles in the case of SAM-1.

Gold Topography and Chemical Reactivity Direct Nanoparticle Assembling. Nanoparticles being able to assemble only on areas containing alkyne groups, the SAM structure may direct the assembling process of nanoparticles. Indeed, nanoparticles assembled preferentially at gold grain junctions where the topography favors interactions with alkyne groups and azido-terminated nanoparticles. It results in rather unidirectional assemblies (chains) from which the nanoparticles assemble in $2 \mathrm{D}$ domains. This assembly process may result from interparticle interactions triggered by larger dipolar moments as long as the nanoparticle assembly grows. ${ }^{59-61}$

Furthermore, nanoparticle domains also grow on areas corresponding to terraces of gold grains. In contrast to grain junctions, the desorption of $\mathrm{S}-\mathrm{CH}_{3}$ at the surface of terraces is longer because of tight packing of self-assembled molecules. ${ }^{11}$ Therefore, nanoparticles can only assemble on terraces for the largest amount of S-CC molecules (>50\%). The presence of nanoparticle domains in the center of terraces in SAM-0.5 is indicative of the replacement of $\mathrm{S}-\mathrm{CH}_{3}$ by $\mathrm{S}-\mathrm{CC}$ molecules. As shown by our computational model, some pure areas of S-CC become large enough for nanoparticle immobilization on terraces than in junctions; it may be triggered by the lower energy of pure S-CC SAM structure.

A larger amount of S-CC in solution contributes to extend nanoparticle assemblies at the surface of SAM-0.8. Gold grain junctions seem to be much more covered and nanoparticle domains are much larger. This result shows that alkyne groups are localized onto both gold grain junctions and gold terraces. The cohabitation with uncovered areas, which represent about $20 \%$ of the SAM surface, agrees with areas containing $\mathrm{S}_{-} \mathrm{CH}_{3}$ molecules. Although it is difficult to tell about the presence of S-CC in these uncovered areas, it may count for half according to theoretical calculations.

The distribution of alkyne terminal groups at the surface of mixed SAMs significantly influenced the spatial arrangement of nanoparticles. Domains of relatively tight packed nanoparticles were formed and grew from gold grain junctions to terraces.

\section{CONCLUSION}

The assembly of magnetic iron oxide nanoparticles was controlled through specific chemical interactions between azide and alkyne groups localized at nanoparticle and SAM surfaces, respectively. The spatial arrangement of nanoparticles was controlled by the structure of mixed SAMs of S-CC and S$\mathrm{CH}_{3}$ molecules. While the characterization of alkyne groups was not possible by usual surface techniques such as XPS and PM-IRRAS, nanoparticles allowed determining spatially the presence of alkyne groups at the monolayer surface. Although a dense monolayer of nanoparticles was obtained onto a SAM$\mathrm{CC}$, intermediate nanoparticle densities were obtained by modulating the $\mathrm{S}-\mathrm{CC} / \mathrm{S}-\mathrm{CH}_{3}$ molar ratio used to prepare 
mixed SAMs. In addition to SEM, the combination of STM measurements and theoretical calculations offered a deeper understanding of the structure of mixed SAMs. First, S-CC $\mathrm{SAM}$ is much more stable than $\mathrm{S}-\mathrm{CH}_{3} \mathrm{SAM}$, which agrees with faster desorption of $\mathrm{S}-\mathrm{CH}_{3}$ molecules. Second, homogeneous mixing of $\mathrm{S}-\mathrm{CC}$ and $\mathrm{S}-\mathrm{CH}_{3}$ is favored against segregation, especially in mixed SAMs with high S-CC content. Therefore, alkyne terminal groups are less accessible than methylene terminal groups because the S-CC alkyl chain is shorter than the $\mathrm{S}-\mathrm{CH}_{3}$ one ( 9 vs 11 carbons). Binding with azideterminated nanoparticles was disfavored and resulted in lower nanoparticle density. Nevertheless, the topography of gold substrates favored significant defect mediated exchange of S$\mathrm{CH}_{3}$ by $\mathrm{S}$-CC molecules. Therefore, above a critical content in $\mathrm{S}$-CC, the formation of large enough alkyne areas favored the assembly of nanoparticles at grain junctions which further extended to terraces. Such a mechanism was triggered by the lower energy of S-CC assemblies than $\mathrm{S}-\mathrm{CH}_{3}$, ones as shown by theoretical calculations. Finally, the magnetic properties of nanoparticle assemblies were studied. Although nanoparticle density increases with alkyne content in mixed SAM, assemblies consisting of relatively large $2 \mathrm{D}$ domains which favored rather strong dipolar interactions. Therefore, the collective magnetic properties of nanoparticles are rather similar whatever the domain size, which means that, above a critical size, dipolar interactions predominate over the size effect of 2D assemblies. Finally, our approach is versatile and can be used for the assembly of a variety of nanoparticles. The fine control of phase segregation in mixed SAMs will pave the way to the patterning of nanoparticles, which is of high interest for advanced applications such as bit patterned recording media or magnetic sensors.

\section{ASSOCIATED CONTENT}

\section{S Supporting Information}

The Supporting Information is available free of charge on the ACS Publications website at DOI: 10.1021/acsanm.8b02152.

TEM micrograph, size distribution, and granulometry measurements for azido-terminated nanoparticles; atomic force micrographs of gold thin film and SAM-0 and SAM-1; survey XPS scan recorded for SAM-0 and SAM-1 (PDF)

\section{AUTHOR INFORMATION}

\section{Corresponding Author}

*E-mail: benoit.pichon@ipcms.unistra.fr.

\section{ORCID $\odot$}

Frederik Tielens: 0000-0002-6760-6176

Spyridon Zafeiratos: 0000-0001-8165-2585

Sylvie Begin-Colin: 0000-0002-2293-2226

Benoit P. Pichon: 0000-0003-3708-6461

Notes

The authors declare no competing financial interest.

\section{ACKNOWLEDGMENTS}

Funding was provided by Direction générale de l'armement (DGA) and Région Alsace for D.T.'s Ph.D. This work was supported by the French Agence Nationale de la Recherche (ANR) under Reference ANR-11-LABX-0058-NIE within the Investissement d'Avenir program ANR-10-IDEX-0002-02. HPC resources from GENCI-[CCRT/CINES/IDRIS]
(Grants 2016-[x2016082022] and 2017- x2017082131) and the CCRE of Université Pierre et Marie Curie were provided for computational calculations. Dr. X. Cattoën from Institut Néel (Grenoble, France) is acknowledge for providing phosphonic acid derivative for nanoparticle functionalization prior to the preparation of azido-terminated nanoparticles.

\section{REFERENCES}

(1) Nie, Z.; Petukhova, A.; Kumacheva, E. Properties and Emerging Applications of Self-Assembled Structures Made from Inorganic Nanoparticles. Nat. Nanotechnol. 2010, 5, 15-25.

(2) Kinge, S.; Crego-Calama, M.; Reinhoudt, D. N. Self-Assembling Nanoparticles at Surfaces and Interfaces. ChemPhysChem 2008, 9, $20-42$.

(3) Singamaneni, S.; Bliznyuk, V. N.; Binek, C.; Tsymbal, E. Y. Magnetic Nanoparticles: Recent Advances in Synthesis, Self-Assembly and Applications. J. Mater. Chem. 2011, 21, 16819-16845.

(4) Neouze, M.-A. Nanoparticle Assemblies: Main Synthesis Pathways and Brief Overview on Some Important Applications. J. Mater. Sci. 2013, 48, 7321-7349.

(5) Bao, N.; Gupta, A. Self-Assembly of Superparamagnetic Nanoparticles. J. Mater. Res. 2011, 26, 111-121.

(6) Smith, R. K.; Lewis, P. A.; Weiss, P. S. Patterning Self-Assembled Monolayers. Prog. Surf. Sci. 2004, 75, 1-68.

(7) Love, J. C.; Estroff, L. A.; Kriebel, J. K.; Nuzzo, R. G.; Whitesides, G. M. Self-Assembled Monolayers of Thiolates on Metals as a Form of Nanotechnology. Chem. Rev. 2005, 105, 1103-1170.

(8) Vericat, C.; Vela, M. E.; Benitez, G.; Carro, P.; Salvarezza, R. C. Self-Assembled Monolayers of Thiols and Dithiols on Gold: New Challenges for a Well-Known System. Chem. Soc. Rev. 2010, 39, $1805-1834$.

(9) van den Brom, C. R.; Arfaoui, I.; Cren, T.; Hessen, B.; Palstra, T. T. M.; De Hosson, J. T. M.; Rudolf, P. Selective Immobilization of Nanoparticles on Surfaces by Molecular Recognition Using Simple Multiple H-Bonding Functionalities. Adv. Funct. Mater. 2007, 17, 2045-2052.

(10) Sakuragi, N.; Yamamoto, S.; Koide, Y. A Self-Assembled Monolayers Assisted Solid-State Conversion of Boehmite Particles to Aluminum Oxide Film. J. Am. Chem. Soc. 2007, 129, 10048-10049.

(11) Pichon, B. P.; Barbillon, G.; Marie, P.; Pauly, M.; Begin-Colin, S. Iron Oxide Magnetic Nanoparticles Used as Probing Agents to Study the Nanostructure of Mixed Self-Assembled Monolayers. Nanoscale 2011, 3, 4696-4705.

(12) Pichon, B. P.; Leuvey, C.; Ihawakrim, D.; Bernard, P.; Schmerber, G.; Begin-Colin, S. Magnetic Properties of Mono- and Multilayer Assemblies of Iron Oxide Nanoparticles Promoted by SAMs. J. Phys. Chem. C 2014, 118, 3828-3837.

(13) Pichon, B. P.; Pauly, M.; Marie, P.; Leuvrey, C.; Begin-Colin, S. Tunable Magnetic Properties of Nanoparticles 2D Assemblies Addressed by Mixed SAMs. Langmuir 2011, 27, 6235-6243.

(14) Bae, S.-S.; Lim, D. K.; Park, J.-I.; Lee, W.-R.; Cheon, J.; Kim, S. Selectively Assembled Co Nanoparticle Stripes Prepared by Covalent Linkage and Microcontact Printing. J. Phys. Chem. B 2004, 108, 2575-2579.

(15) Kolb, H. C.; Finn, M. G.; Sharpless, K. B. Click Chemistry: Diverse Chemical Function from a Few Good Reactions. Angew. Chem., Int. Ed. 2001, 40, 2004-2021.

(16) White, M. A.; Johnson, J. A.; Koberstein, J. T.; Turro, N. J. Toward the Syntheses of Universal Ligands for Metal Oxide Surfaces: Controlling Surface Functionality through Click Chemistry. J. Am. Chem. Soc. 2006, 128, 11356-11357.

(17) Rengifo, H. R.; Chen, L.; Grigoras, C.; Ju, J.; Koberstein, J. T. Click-Functional" Block Copolymers Provide Precise Surface Functionality via Spin Coating. Langmuir 2008, 24, 7450-7456.

(18) Prakash, S.; Long, T. M.; Selby, J. C.; Moore, J. S.; Shannon, M. A. Click" Modification of Silica Surfaces and Glass Microfluidic Channels. Anal. Chem. 2007, 79, 1661-1667. 
(19) Toulemon, D.; Pichon, B. P.; Cattoen, X.; Man, M. W. C.; Begin-Colin, S. 2D Assembly of Non-Interacting Magnetic Iron Oxide Nanoparticles via "Click" Chemistry. Chem. Commun. 2011, 47, 11954-11956.

(20) Toulemon, D.; Pichon, B. P.; Leuvrey, C.; Zafeiratos, S.; Papaefthimiou, V.; Cattoen, X.; Begin-Colin, S. Fast Assembling of Magnetic Iron Oxide Nanoparticles by Microwave-Assisted Copper(I) Catalyzed Alkyne-Azide Cycloaddition (CuAAC). Chem. Mater. 2013, 25, 2849-2854.

(21) Williams, M. G.; Teplyakov, A. V. Building High-Coverage Monolayers of Covalently Bound Magnetic Nanoparticles. Appl. Surf. Sci. 2016, 388 (Part A), 461-467.

(22) Liu, Y.; Williams, M. G.; Miller, T. J.; Teplyakov, A. V. Nanoparticle Layer Deposition for Highly Controlled Multilayer Formation Based on High-Coverage Monolayers of Nanoparticles. Thin Solid Films 2016, 598, 16-24.

(23) Rydzek, G.; Toulemon, D.; Garofalo, A.; Leuvrey, C.; Dayen, J.F.; Felder-Flesch, D.; Schaaf, P.; Jierry, L.; Begin-Colin, S.; Pichon, B. P.; et al. Selective Nanotrench Filling by One-Pot Electroclick SelfConstructed Nanoparticle Films. Small 2015, 11, 4638-4642.

(24) Kinge, S.; Gang, T.; Naber, W. J. M.; van der Wiel, W. G.; Reinhoudt, D. N. Magnetic Nanoparticle Assembly on Surfaces Using Click Chemistry. Langmuir 2011, 27, 570-574.

(25) Toulemon, D.; Rastei, M. V.; Schmool, D.; Garitaonandia, J. S.; Lezama, L.; Cattoën, X.; Bégin-Colin, S.; Pichon, B. P. Enhanced Collective Magnetic Properties Induced by the Controlled Assembly of Iron Oxide Nanoparticles in Chains. Adv. Funct. Mater. 2016, 26, 2454-2462.

(26) Bumm, L. A.; Arnold, J. J.; Charles, L. F.; Dunbar, T. D.; Allara, D. L.; Weiss, P. S. Directed Self-Assembly to Create Molecular Terraces with Molecularly Sharp Boundaries in Organic Monolayers. J. Am. Chem. Soc. 1999, 121, 8017-8021.

(27) Chen, S.; Li, L.; Boozer, C. L.; Jiang, S. Controlled Chemical and Structural Properties of Mixed Self-Assembled Monolayers of Alkanethiols on $\mathrm{Au}(111)$. Langmuir 2000, 16, 9287-9293.

(28) Choi, I.; Kim, Y.; Kang, S. K.; Lee, J.; Yi, J. Phase Separation of a Mixed Self-Assembled Monolayer Prepared via a Stepwise Method. Langmuir 2006, 22, 4885-4889.

(29) Zhang, H.; Grim, P. C. M.; Liu, D.; Vosch, T.; De Feyter, S.; Wiesler, U. M.; Berresheim, A. J.; Mullen, K.; Van Haesendonck, C.; Vandamme, N.; et al. Probing Carboxylic Acid Groups in Replaced and Mixed Self-Assembled Monolayers by Individual Ionized Dendrimer Molecules: An Atomic Force Microscopy Study. Langmuir 2002, 18, 1801-1810.

(30) Goldmann, C.; Ribot, F.; Peiretti, L. F.; Quaino, P.; Tielens, F.; Sanchez, C.; Chanéac, C.; Portehault, D. Quantified Binding Scale of Competing Ligands at the Surface of Gold Nanoparticles: The Role of Entropy and Intermolecular Forces. Small 2017, 13, 1604028.

(31) Tielens, F.; Costa, D.; Humblot, V.; Pradier, C.-M. Characterization of $\omega$-Functionalized Undecanethiol Mixed Self-Assembled Monolayers on $\mathrm{Au}(111)$ : A Combined Polarization Modulation Infrared Reflection-Absorption Spectroscopy/X-Ray Photoelectron Spectroscopy/Periodic Density Functional Theory Study. J. Phys. Chem. C 2008, 112, 182-190.

(32) Meena, S. K.; Goldmann, C.; Nassoko, D.; Seydou, M.; Marchandier, T.; Moldovan, S.; Ersen, O.; Ribot, F.; Chanéac, C.; Sanchez, C.; et al. Nanophase Segregation of Self-Assembled Monolayers on Gold Nanoparticles. ACS Nano 2017, 11, 7371-7381.

(33) Horcas, I.; Fernandez, R.; Gomez-Rodriguez, J. M.; Colchero, J.; Gomez-Herrero, J.; Baro, A. M. WSXM: A Software for Scanning Probe Microscopy and a Tool for Nanotechnology. Rev. Sci. Instrum. 2007, 78, 013705-013708.

(34) Luo, W.; Zafeiratos, S. Tuning Morphology and Redox Properties of Cobalt Particles Supported on Oxides by an in between Graphene Layer. J. Phys. Chem. C 2016, 120, 14130-14139.

(35) Kresse, G.; Hafner, J. Ab Initio. Phys. Rev. B: Condens. Matter Mater. Phys. 1993, 47, 558-561.
(36) Kresse, G.; Hafner, J. Norm-Conserving and Ultrasoft Pseudopotentials for First-Row and Transition Elements. J. Phys.: Condens. Matter 1994, 6, 8245-8257.

(37) Blöchl, P. E. Projector Augmented-Wave Method. Phys. Rev. B: Condens. Matter Mater. Phys. 1994, 50, 17953-17979.

(38) Perdew, J. P.; Burke, K.; Ernzerhof, M. Generalized Gradient Approximation Made Simple. Phys. Rev. Lett. 1996, 77, 3865-3868.

(39) Grimme, S.; Antony, J.; Ehrlich, S.; Krieg, H. A Consistent and Accurate Ab Initio Parametrization of Density Functional Dispersion Correction (DFT-D) for the 94 Elements H-Pu. J. Chem. Phys. 2010, 132, 154104.

(40) Luque, N. B.; Santos, E.; Andres, J.; Tielens, F. Effect of Coverage and Defects on the Adsorption of Propanethiol on $\mathrm{Au}(111)$ Surface: A Theoretical Study. Langmuir 2011, 27, 14514-14521.

(41) Dolci, M.; Bryche, J.-F.; Leuvrey, C.; Zafeiratos, S.; Gree, S.; Begin-Colin, S.; Barbillon, G.; Pichon, B. P. Robust Clicked Assembly Based on Iron Oxide Nanoparticles for a New Type of SPR Biosensor. J. Mater. Chem. C 2018, 6, 9102-9110.

(42) Castner, D. G.; Hinds, K.; Grainger, D. W. X-Ray Photoelectron Spectroscopy Sulfur 2p Study of Organic Thiol and Disulfide Binding Interactions with Gold Surfaces. Langmuir 1996, 12, 50835086.

(43) Pasquali, L.; Terzi, F.; Seeber, R.; Nannarone, S.; Datta, D.; Dablemont, C.; Hamoudi, H.; Canepa, M.; Esaulov, V. A. UPS, XPS, and NEXAFS Study of Self-Assembly of Standing 1,4-Benzenedimethanethiol SAMs on Gold. Langmuir 2011, 27, 4713-4720.

(44) Joseph, Y.; Guse, B.; Nelles, G. Aging of 1, $\omega$-Alkyldithiol Interlinked Au Nanoparticle Networks. Chem. Mater. 2009, 21, 16701676.

(45) Heister, K.; Zharnikov, M.; Grunze, M.; Johansson, L. S. O. Adsorption of Alkanethiols and Biphenylthiols on $\mathrm{Au}$ and $\mathrm{Ag}$ Substrates: A High-Resolution X-Ray Photoelectron Spectroscopy Study. J. Phys. Chem. B 2001, 105, 4058-4061.

(46) Luo, W.; Zafeiratos, S. CHAPTER 5:XPS Characterization of Metal-Free Functionalized Carbons. Metal-free Functionalized Carbons in Catalysis 2018, 138-176.

(47) Teschner, D.; Vass, E.; Hävecker, M.; Zafeiratos, S.; Schnörch, P.; Sauer, H.; Knop-Gericke, A.; Schlögl, R.; Chamam, M.; Wootsch, A. Alkyne Hydrogenation over Pd Catalysts: A New Paradigm. J. Catal. 2006, 242, 26-37.

(48) Hamoudi, H.; Chesneau, F.; Patze, C.; Zharnikov, M. ChainLength-Dependent Branching of Irradiation-Induced Processes in Alkanethiolate Self-Assembled Monolayers. J. Phys. Chem. C 2011, $115,534-541$.

(49) Lee, S.; Shon, Y.-S.; Colorado, R.; Guenard, R. L.; Lee, T. R.; Perry, S. S. The Influence of Packing Densities and Surface Order on the Frictional Properties of Alkanethiol Self-Assembled Monolayers (SAMs) on Gold: A Comparison of SAMs Derived from Normal and Spiroalkanedithiols. Langmuir 2000, 16, 2220-2224.

(50) Nuzzo, R. G.; Zegarski, B. R.; Dubois, L. H. Fundamental Studies of the Chemisorption of Organosulfur Compounds on Gold(111). Implications for Molecular Self-Assembly on Gold Surfaces. J. Am. Chem. Soc. 1987, 109, 733-740.

(51) Paoprasert, P.; Spalenka, J. W.; Peterson, D. L.; Ruther, R. E.; Hamers, R. J.; Evans, P. G.; Gopalan, P. Grafting of Poly(3Hexylthiophene) Brushes on Oxides Using Click Chemistry. J. Mater. Chem. 2010, 20, 2651-2658.

(52) Mizutani, W.; Ishida, T.; Tokumoto, H. Monte Carlo Simulation of Phase-Separated Self-Assembled Films. Appl. Surf. Sci. 1998, 130-132, 792-796.

(53) Takami, T.; Delamarche, E.; Michel, B.; Gerber, C.; Wolf, H.; Ringsdorf, H. Recognition of Individual Tail Groups in SelfAssembled Monolayers. Langmuir 1995, 11, 3876-3881.

(54) Nassoko, D.; Seydou, M.; Goldmann, C.; Chanéac, C.; Sanchez, C.; Portehault, D.; Tielens, F. Rationalizing the Formation of Binary Mixed Thiol Self-Assembled Monolayers. Mater. Today Chem. 2017, 5, 34-42. 
(55) Guesmi, H.; Luque, N. B.; Santos, E.; Tielens, F. Does the S-H Bond Always Break after Adsorption of an Alkylthiol on $\mathrm{Au}(111)$ ? Chem. - Eur. J. 2017, 23, 1402-1408.

(56) Baaziz, W.; Pichon, B. P.; Fleutot, S.; Liu, Y.; Lefevre, C.; Greneche, J.-M.; Toumi, M.; Mhiri, T.; Begin-Colin, S. Magnetic Iron Oxide Nanoparticles: Reproducible Tuning of the Size and Nanosized-Dependent Composition, Defects, and Spin Canting. J. Phys. Chem. C 2014, 118, 3795-3810.

(57) Pauly, M.; Pichon, B. P.; Panissod, P.; Fleutot, S.; Rodriguez, P.; Drillon, M.; Begin-Colin, S. Size Dependent Dipolar Interactions in Iron Oxide Nanoparticle Monolayer and Multilayer LangmuirBlodgett Films. J. Mater. Chem. 2012, 22, 6343-6350.

(58) Maidenberg, Y.; Zhang, S.; Luo, K.; Akhavein, N.; Koberstein, J. T. Mixed Silane Monolayers for Controlling the Surface Areal Density of Click-Reactive Alkyne Groups: A Method to Assess Preferential Surface Adsorption on Flat Substrates and a Method to Verify Compositional Homogeneity on Nanoparticles. Langmuir 2013, 29, 11959-11965.

(59) Klokkenburg, M.; Vonk, C.; Claesson, E. M.; Meeldijk, J. D.; Erne, B. H.; Philipse, A. P. Direct Imaging of Zero-Field Dipolar Structures in Colloidal Dispersions of Synthetic Magnetite. J. Am. Chem. Soc. 2004, 126, 16706-16707.

(60) Butter, K.; Bomans, P. H. H.; Frederik, P. M.; Vroege, G. J.; Philipse, A. P. Direct Observation of Dipolar Chains in Iron Ferrofluids by Cryogenic Electron Microscopy. Nat. Mater. 2003, 2, $88-91$.

(61) Toulemon, D.; Liu, Y.; Cattoën, X.; Leuvrey, C.; Bégin-Colin, S.; Pichon, B. P. Enhanced Collective Magnetic Properties in 2D Monolayers of Iron Oxide Nanoparticles Favored by Local Order and Local 1D Shape Anisotropy. Langmuir 2016, 32, 1621-1628. 